\title{
REMOTE SENSING EVALUATION OF ECOLOGICAL ENVIRONMENT OF ANQING CITY BASED ON REMOTE SENSING ECOLOGICAL INDEX
}

\author{
Xiaonan $\mathrm{Niu}^{1, *}$, Yunfeng $\mathrm{Li}^{1}$ \\ Nanjing Center, China Geology Survey, Nanjing, 210016 - niuxiaonan@mail.bnu.edu.cn, liyf@mail.cgs.gov.cn
}

Commission III, ICWG III/7

KEY WORDS: Remote Sensing Ecological Index, Principle Component Analysis, Eco-environmental Quality

\begin{abstract}
:
Figuring out the regional ecological environment quality and ecological change is critical for ecological environment monitoring and management and urban construction planning. Based on the remote sensing ecological index (RESI), we evaluate the ecological quality and ecological change from 1999 to 2019 of Anqing city. Multi-temporal Landsat images are used to extract the four indicators of humidity, vegetation, heat and dryness, respectively. Then the RSEI is calculated by principal component analysis. The results show that the ecological quality of Anqing city declined from 1999 to 2019 and then grew slowly from 2009 to 2019. The eco-environmental quality of Anqing city dropped slightly from 1999 to 2019, and the regions with worse quality grades exceeded those becoming better. Particularly, we find that from 1999 to 2009 , the area where the ecological quality became better made up $18.31 \%$ of the urban area, while the worse ecological area accounted for $29.68 \%$ of the urban area; from 2009 to 2019, the area of improved ecological environment reached $24.35 \%$, while the area of degraded quality constituted $41.36 \%$. Land-use changes dominated eco-environmental quality. The areas of poor eco-environmental quality expanded in residential regions and eco-environmental quality of mountainous area improved since returning cultivated land in steep hills into forest. The RSEI results are expected to provide a quantitative foundation for planning sustainable development and the rational use of resources in Anqing city.
\end{abstract}

\section{INTRODUCTION}

Since the implementation of the policy of reform and opening up, urbanization process of China has been rising. A series of environmental problems such as arable land degradation, water pollution, air pollution, and urban heat island, caused by the rapid expansion of urban areas have gradually become social concerns. Identifying and evaluating the status of ecological environment quality is a great of significance for ecological environment protection. With the development of remote sensing technology, the methods for monitoring the changes in the urban ecological environment vary from the perspective of urban heat island effect, land use/cover changes, vegetation index changes, etc. Monitoring of urban ecological environment by remote sensing technology is a complex task. The common methods of regional eco-environmental quality evaluation are usually based on a single indicator, such as relative indicator method (Ye and Liu, 2000), fuzzy assessment method (Fu et al., 2005), analytical hierarchy process ( $\mathrm{Li}, 2009)$ and related analysis method (Gao et al., 1999). However, these studies only consider the impact of a single factor on the environment, or subjectively define the weight of each factor, which fail to consider the complexity of factors affecting the ecological environment. The remote sensing ecological index RSEI proposed by $\mathrm{Xu}$ comprehensively considers various factors such as vegetation coverage, urban construction and surface temperature, and is suitable for comprehensive evaluation of regional ecological conditions $(\mathrm{Xu}$, 2013). RSEI takes four important factors of humidity, greenness, heat and dryness as evaluation indicators and determines the contribution of each indicator to ecological quality through the coupling of principal components. Compared with the method of subjectively determining the index weight, it is more objective, and has obtained good experimental results in the application of soil erosion areas and cities (Zhang et al.,2015; Wang et al., 2016;
$\mathrm{Xu}, 2013)$. Therefore, in this paper, the RSEI index is used to study the ecological environment of the Anqing City, Anhui Province, China to explore the characteristics of spatial and temporal changes of the ecological environment and its driving factors in the process of high-speed urbanization, aiming to provide some support for regional environmental protection.

\section{STUDY AREA AND DATA}

\subsection{Study area}

Anqing City, which is located in the southwest of Anhui Province, lies on the north side of the Dabie Mountains and the south of the Yangtze River, as shown in Figure 1. Located in the north subtropical monsoon humid climate zone, it has the characteristics of distinct seasons and humid climate. The annual average temperature is $16.0 \mathrm{C}^{\circ}-16.5 \mathrm{C}^{\circ}$, the annual rainfall is about $1300 \mathrm{~mm}$. The terrain is dominated by mountains and hills, and the east is the alluvial plain of the Yangtze River. Anqing city, as one of cities of the Yangtze River Delta city group, developed rapidly over years. Urban expansion of Anqing city has drastically changed the land surface and will inevitably have an impact on the ecological environment.

\subsection{Data}

Landsat images of the Anqing City taken from 1999, 2009 and 2019, freely available online from the USGS (https://earthexplorer.usgs.gov), were surveyed to evaluate the ecological environment. Landsat images have $30 \mathrm{~m} /$ pixel resolution and are taken every 16 days (Pekel et al., 2016). The Landsat images were selected to have minimum or no cloud cover over the study area and level 1T (L1T) products were downloaded (Table 1).

* Corresponding author 


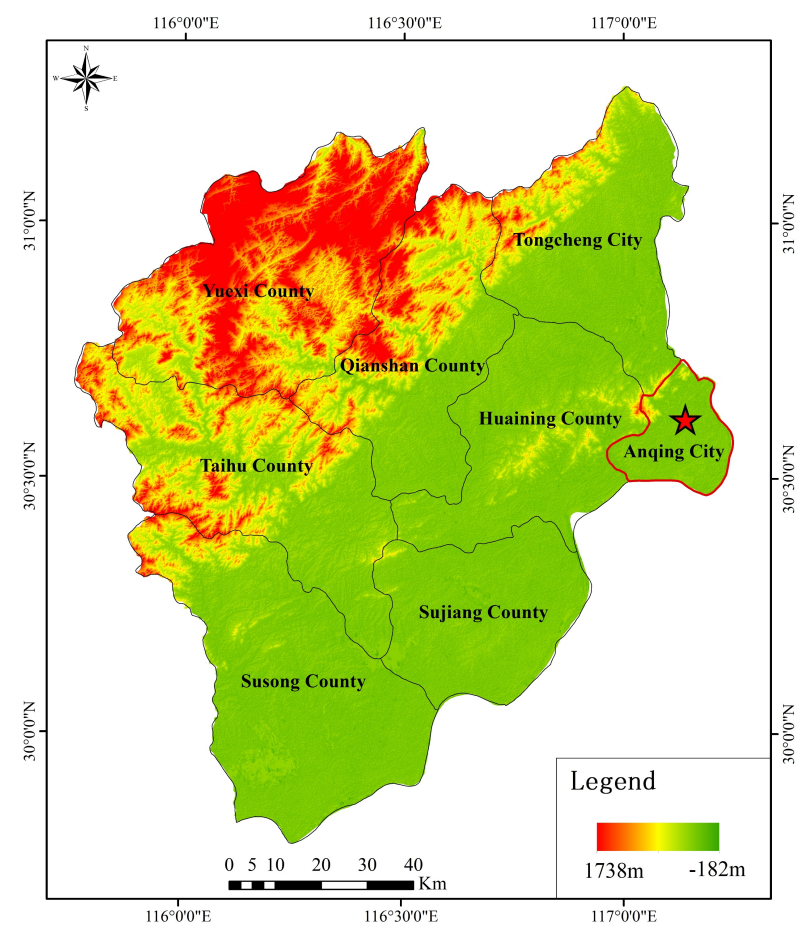

Figure 1. The location of the study area

\begin{tabular}{ccc}
\hline Sensor & Year & Date \\
\hline TM & 1999 & 06 Apr, 15 May \\
TM & 2009 & 16 Mar, 08 Apr \\
OLI & 2019 & 12 Mar, 19 Mar \\
\hline
\end{tabular}

Table 1. Landsat images used in different seasons during the 30 year period (row 157, paths 38 and 39)

L1T Landsat images have been calibrated using best available radiometric calibration methods (Chander, et al., 2009) and typically have geolocation accuracy better than $30 \mathrm{~m}$. Therefore, no further geometric correction was performed for the selected images. An atmospheric correction and a conversion of the brightness values from radiance to reflectance (Vahtmäe and Kutser 2013; Feyisa et al. 2014; Bernardo et al. 2017) were performed using FLAASH (Fast Line-ofsight Atmospheric Analysis of Spectral Hypercubes) module in ENVI v. 5.3 (Othman et al. 2018).

\section{METHODS}

Four indexes of humidity, greenness, heat and dryness are extracted from Landsat images, respectively. Then the RSEI index is calculated through principle components analysis (PCA), which is designed to evaluate the regional ecological environment quality changes quantitatively from 1999 to 2019.

\subsection{Wetness Index}

The humidity index drives from the humidity component transformed by the tassel cap to indicate the moisture information of the soil and vegetation. The equation is as follows. Wet $_{1999 / 2009}=0.0315 \rho_{\text {blue }}+0.2021 \rho_{\text {green }}+0.3012 \rho_{\text {red }}+$
$0.1594 \rho_{\text {NIR }}-0.6806 \rho_{\text {SWIR } 1}-0.6109 \rho_{\text {SWIR } 2}$
$W_{\text {et }} t_{2019}=0.1511 \rho_{\text {blue }}+0.1973 \rho_{\text {green }}+0.3283 \rho_{\text {red }}+$ $0.3407 \rho_{\text {NIR }}-0.7117 \rho_{\text {SWIR } 1}-0.4559 \rho_{\text {SWIR } 2}$

where $\rho_{\text {blue }}, \rho_{\text {green }}, \rho_{\text {red }}, \rho_{\text {NIR }}, \rho_{\text {SWIR } 1}, \rho_{\text {SWIR } 2}$ denote the reflectance of blue, green, red, NIR, SWIR1, and SWIR 2 spectral bands respectively.

\subsection{Vegetation Index}

NDVI is one of the most successful of many attempts to simply and quickly identify vegetated areas and their conditions and used to quantify the photosynthetic capacity of plant canopies.

$$
N D V I=\frac{\rho_{N I R}-\rho_{\text {red }}}{\rho_{N I R}+\rho_{\text {red }}}
$$

\subsection{Heat Index}

Land surface temperature (LST) is an important parameter that indicates the exchange of material energy between the surface and the atmosphere. The satellite-derived LST datasets are also used for a variety of applications including large-scale ecosystem disturbance detection (Mildrexler et al., 2009), drought monitoring (Rhee et al., 2010), land cover monitoring (Julien and Sobrino, 2009; Karnieli et al., 2010), biodiversity studies (Albright et al., 2011), and urban heat island effects (Jin, 2012). Split-window algorithm is used to obtain LST in different periods.

\subsection{Dryness Index}

Considering the impact of bare soil and buildings on ecoenvironment, the dryness index (NDSI) is calculated from the average of the bare soil index (BI) and the index-based built-up index (IBI), which are normalized between 0 and 1 .

$$
\begin{aligned}
& B I=\frac{\left(\rho_{\text {SWIR } 1}+\rho_{\text {red }}\right)-\left(\rho_{\text {NIR }}+\rho_{\text {blue }}\right)}{\left(\rho_{\text {SWIR } 1}+\rho_{\text {red }}\right)+\left(\rho_{\text {NIR }}+\rho_{\text {blue }}\right)} \\
& I B I=\frac{\frac{2 \rho_{\text {SWIR } 1}}{\rho_{S W I R 1}+\rho_{N I R}}-\frac{\rho_{\text {NIR }}}{\rho_{\text {NIR }}+\rho_{\text {red }}}+\frac{\rho_{\text {green }}}{\rho_{\text {green }}+\rho_{S W I R 1} 1}}{\frac{2 \rho_{S W I R 1}}{\rho_{S W I R 1}+\rho_{N I R}}+\frac{\rho_{\text {NIR }}}{\rho_{N I R}+\rho_{\text {red }}}+\frac{\rho_{\text {green }}}{\rho_{\text {green }}+\rho_{S W I R 1}}} \\
& N D S I=\frac{B I+I B I}{2}
\end{aligned}
$$

\subsection{RSEI Index}

The key to constructing RSEI index is to reflect not only individual indicators but also comprehensive conditions of ecoenvironment. Principal component analysis can transform the original multiple variables into a few comprehensive variables, which not only eliminates the correlation between the variables, but also avoids disadvantages of subjective weight setting methods [25]. Taking account of the impact of a large area of water on computing results, the water area was masked. Then the four above indicators of humidity, greenness, NDSI and LST which are normalized between $0-1$ are combined for PCA calculation. The results are shown as Table 2 .

\begin{tabular}{cccccc}
\hline \multirow{2}{*}{ Period } & Indicator & PC1 & PC2 & PC3 & PC4 \\
\hline \multirow{4}{*}{1999} & wetness & 0.45 & -0.25 & 0.22 & -0.83 \\
& vegetation & 0.72 & -0.37 & 0.21 & 0.55 \\
& heat & -0.29 & 0.07 & 0.95 & 0.06 \\
& dryness & -0.45 & -0.89 & -0.06 & 0.01 \\
\hline
\end{tabular}




\begin{tabular}{|c|c|c|c|c|c|}
\hline & $\begin{array}{c}\text { accumulative } \\
\text { variance } \\
\text { contribution (\%) }\end{array}$ & 71.87 & 88.78 & 99.72 & 100 \\
\hline \multirow{5}{*}{2009} & wetness & 0.52 & 0.69 & 0.50 & 0.04 \\
\hline & vegetation & 0.62 & -0.41 & -0.12 & 0.66 \\
\hline & heat & -0.29 & 0.58 & -0.53 & 0.54 \\
\hline & dryness & -0.51 & -0.13 & 0.67 & 0.52 \\
\hline & $\begin{array}{c}\text { accumulative } \\
\text { variance } \\
\text { contribution (\%) }\end{array}$ & 71.12 & 85.89 & 97.56 & 100 \\
\hline \multirow{5}{*}{2019} & wetness & 0.40 & 0.48 & -0.48 & 0.61 \\
\hline & vegetation & 0.56 & -0.28 & 0.67 & 0.39 \\
\hline & heat & -0.36 & 0.74 & 0.55 & 0.09 \\
\hline & dryness & -0.63 & -0.37 & -0.03 & 0.68 \\
\hline & $\begin{array}{l}\text { accumulative } \\
\text { variance } \\
\text { contribution (\%) } \\
\end{array}$ & 77.48 & 86.79 & 99.08 & 100 \\
\hline
\end{tabular}

Table 2. Results of PCA analysis

Table 2 shows that the eigen values of NDVI and Wetness indexes for $\mathrm{PC} 1$ are positive, indicating that the two factors play a positive role in assessing the quality of the ecological environment, while the eigen values of LST and NDSI for PC1 are negative, which means that the two indexes play the opposite role compared with the former. Since the first principal component encompassed large percentage (over $70 \%$ ) of the total variation, it synthesizes the characteristics of the four indicators to the greatest extent and can reflect ecological phenomena reasonably. Therefore, it can be used to represent RSEI index.

\section{RESULTS AND DISCUSSION}

\subsection{Overall Analysis}

The results show that the average value of RSEI of Anqing city in 1999, 2009, and 2019 was $0.5485,0.4834$, and 0.5022 , respectively (Figure 1). On the whole, the ecological quality of Anqing city declined from 1999 to 2019 and then rose slowly from 2009 to 2019. The RSEI images of the three periods are shown as Figure 2. The eco-environmental situations of Anqing city deteriorated slightly from 1999 to 2019. What is more obvious is that the ecological environment in the northwest Dabie Mountainous area had become worse. Meanwhile, the ecological quality of the hilly area located in Huaining county had been decreasing. Besides, it can be seen from Figure 2 that urban area in Tongchen city and Anqing suffered from degradation of ecological environment quality.

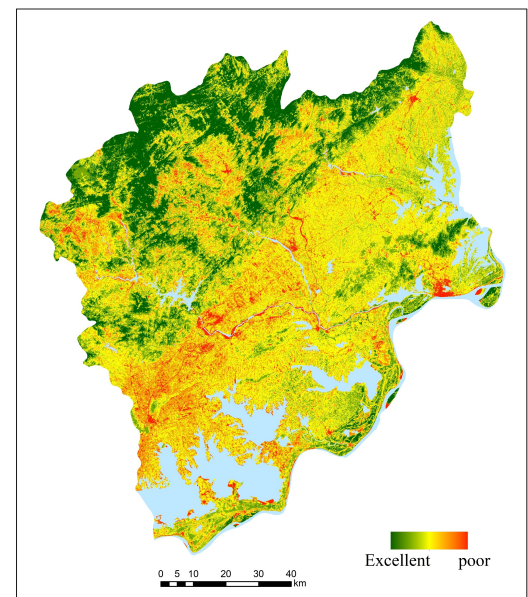

a. RSEI image of 1999

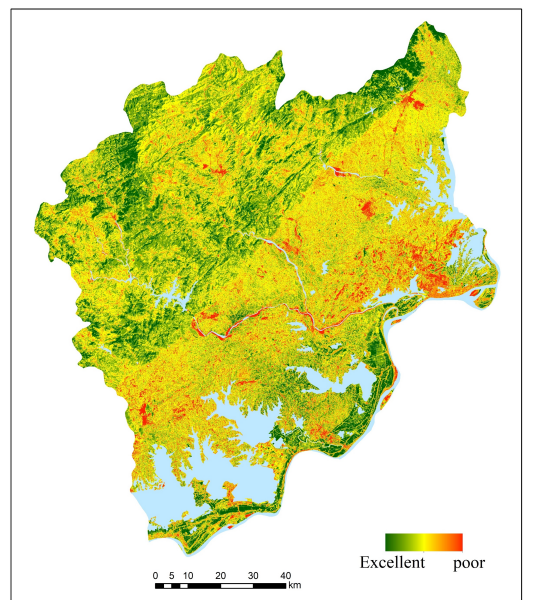

b. RSEI image of 2009

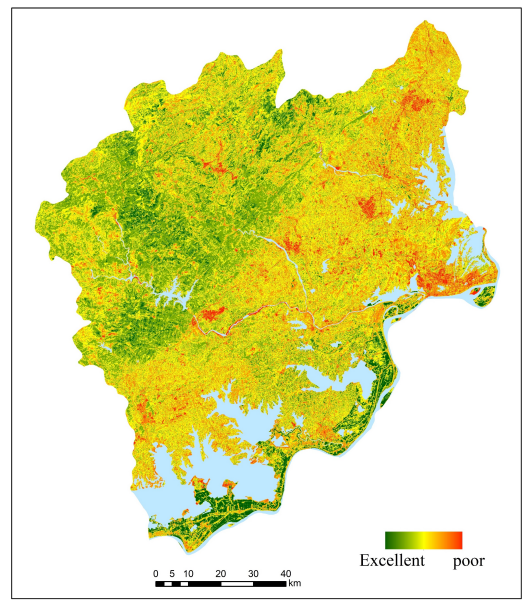

c. RSEI image of 2019

Figure 2. RSEI images of Anqing city from 1999 to 2019.

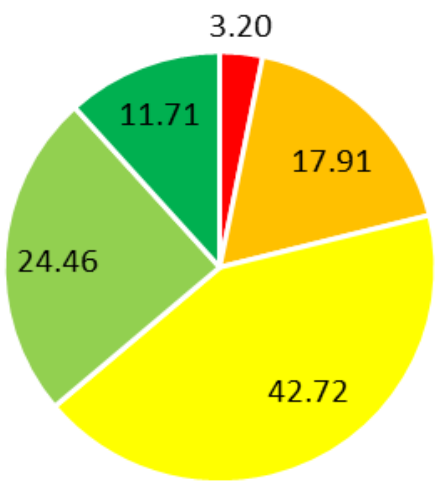

a. Statistics in 1999

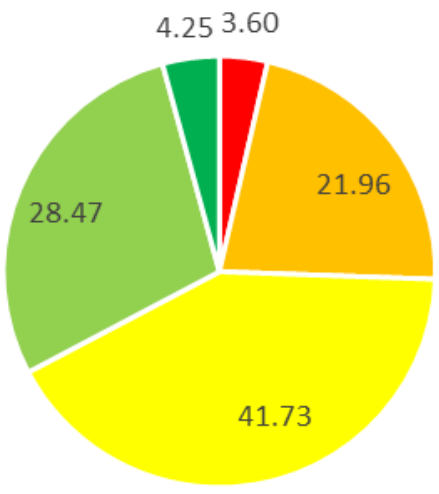

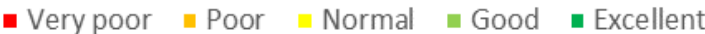

b. Statistics in 2009

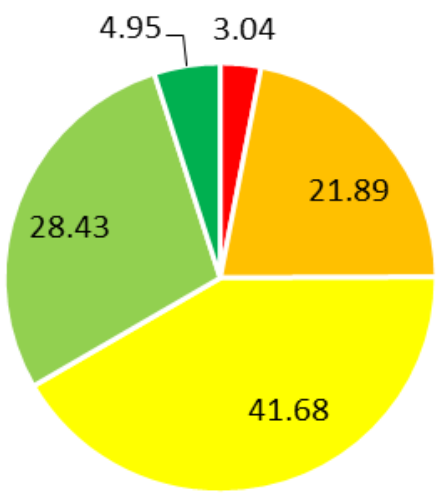

c. Statistics in 2019

Figure 3. Relative area of each eco-environmental quality class related to the total area of Anqing city in 1999, 2009 , and 2019 


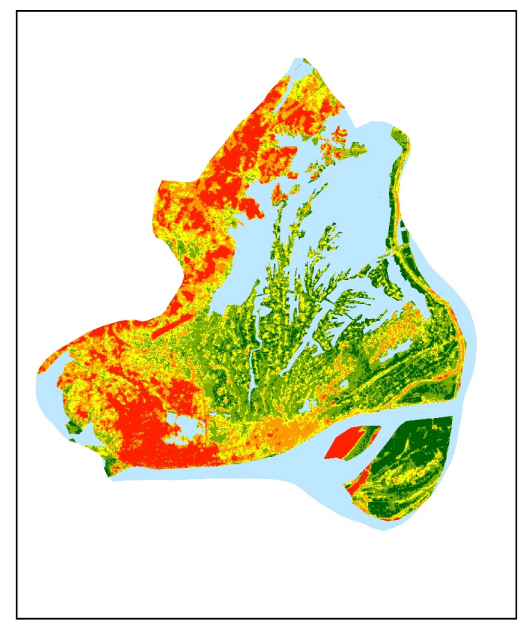

1999

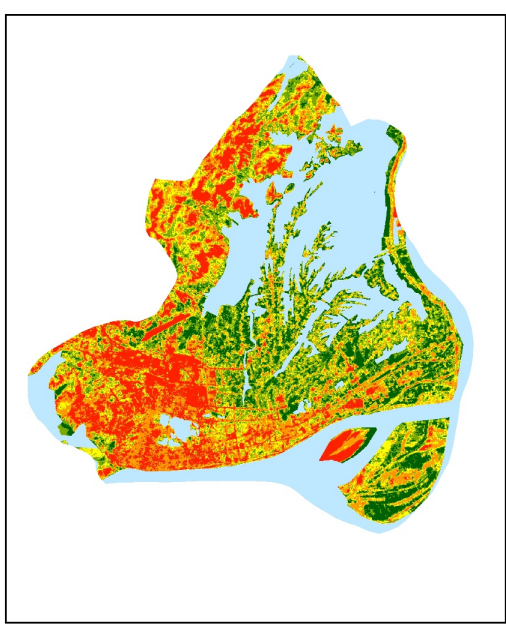

2009

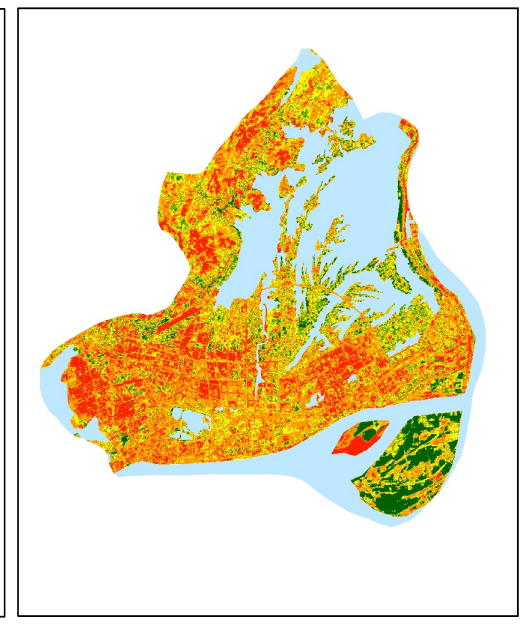

2019

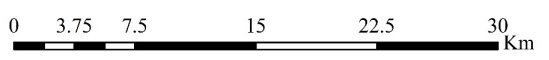

Legend

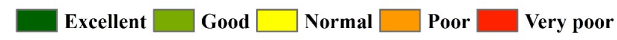

Figure 4. Spatial distribution of five eco-environmental quality classes for urban area of Anqing in 1999, 2009, and 2019.

\subsection{Levelled-RSEI Analysis}

Based on the classification method proposed by $\mathrm{Xu}$, according to [0 0.2), [0.2-0.4), [0.4-0.6), [[ $0.6 \sim 0.8)$, [0.8 1), RSEI image is divided into 5 classes, namely very poor, poor, normal, good, and excellent level. As can be seen from Figure 3, the proportion of areas with the excellent class of ecological quality decreased sharply from $11.71 \%$ to $4.25 \%$ between 1999 and 2009 , and grew slightly to 4.95 in 2019 . The area with poor level of ecoenvironment quality saw an opposite trend. The proportion had rose from $17.91 \%$ to $21.96 \%$ between 1999 and 2009, and dropped to $21.89 \%$ in 2019 . Similarly, the area with the very poor grade witnessed a rising trend by 2009 , growing from $3.20 \%$ to $3.60 \%$, while fell to $3.04 \%$ in 2019 . According to the analysis, we hold that the regional ecological quality improved from 2009 to 2019 .

Particularly, we take the urban area as the area of interest which is marked with the red boundary and star in Figure1, and find that from 1999 to 2009 , the area where the ecological quality became better made up $18.31 \%$ of the urban area, while the worse ecological area accounted for $29.68 \%$ of the urban area; from 2009 to 2019, the area of improved ecological environment reached $24.35 \%$, while the area of degraded quality constituted $41.36 \%$ (Figure 4).

\section{CONCLUSION}

Between 1999 and 2019, the ecological quality of Anqing city witnessed a fluctuation, which declined by 2009 and then gradually improved in the next 10 years. The government has been paying more and more attention to environmental protection, stopping the trend of continuous deterioration of the ecological environment. Land-use changes dominated eco-environmental quality variations during the period between 1999 and 2019 in Anqing city: areas of poor eco-environmental quality expanded in residential regions and eco-environmental quality of mountainous area improved since returning cultivated land in steep hills into forest.

Vegetation and wetness index have a positive effect on RSEI, while heat and dryness indicator have a negative effect on RSEI.
Therefore, in order to improve the urban ecological environment, in addition to controlling the expansion of the urban area, it is critical to increase vegetation coverage in the city.

\section{ACKNOWLEDGEMENTS}

This research was funded by the National Natural Science Foundation of China (Grant No. 41901310) and Geological Survey Project of China (Grant No.DD20189250).

\section{REFERENCES}

Albright, T. P., Pidgeon, A. M., Rittenhouse, C. D., et al., 2011. Heat waves measured with MODIS land surface temperature data predict changes in avian community structure. Remote Sensing of Environment, 115, 245-254.

Bernardo, N.,Watanabe, F., Rodrigues, T., et al., 2017. Atmospheric correction issues for retrieving total suspended matter concentrations in inland waters using OLI/Landsat-8 image. Advances in Space Research, 59(9), 2335-2348.

Chander, G., Markham, B.L., Helder, D. L., 2009. Summary of current radiometric calibration coefficients for Landsat MSS, TM, ETM+, and EO-1 ALI sensors. Remote Sensing of Environment, 113, 893-903.

Feyisa, G. L., Meilby, H., Fensholt, R., et al., 2014. Automated water extraction index: a new technique for surface water mapping using Landsat imagery. Remote Sensing of Environment, 140, 23-35.

Fu Z, Zhou Y. X., Liu D. W. ,2005. Research on spatial fuzzy comprehensive assessment of eco-environmental quality: A case study in the west of Jilin Province. Journal of Arid Land Resources and Environment, 19 (5): 97-102.

Gao Z. Q., Liu J. Y., Zhuang D. F., 1999. The relations analysis between ecological environmental quality of Chinese land resources and population. Journal of Remote Sensing, 3(1): 6670. 
Jin, M. S., 2012. Developing an index to measure urban heat island effect using satellite land skin temperature and land cover observations. Journal of Climate, 25: 6193-6201.

Julien, Y., Sobrino, J. A., 2009. The yearly land cover dynamics (YLCD) method: An analysis of global vegetation from NDVI and LST parameters. Remote Sensing of Environment,113:329334.

Karnieli, A., Agam, N., Pinker, R. T., et al., 2010. Use of NDVI and land surface temperature for drought assessment: Merits and limitations. Journal of Climate, 23, 618-633.

Li K., 2009. Application of analytical hierarchy process to integrate evaluation of eco-environment. Environmental Science and Technology,32( 2) : 183-185 .

Mildrexler, D. J., Zhao, M., Running, S. W., 2009. Testing a MODIS global disturbance index across North America. Remote Sensing of Environment, 113: 2103-2117.

Othman, Y., Steele, C., Hilaire, R. S., 2018. Surface reflectance climate data records (CDRs) is a reliable Landsat ETM+ source to study chlorophyll content in pecan orchards. Journal of the Indian Society of Remote Sensing, 46(2):211-218.

Pekel, J.-F., Cottam, A., Gorelick, N., et al., 2016. Highresolution mapping of global surface water and its long-term changes. Nature, 540(7633): 418-422.
Rhee, J., Im, J., Carbone, G. J., 2010. Monitoring agricultural drought for arid and humid regions using multi-sensor remote sensing data. Remote Sensing of Environment, 114:2875-2887.

Vahtmäe, E., Kutser, T., 2013. Classifying the Baltic Sea shallow water habitats using image-based and spectral library methods. Remote Sensing, 5: 2451-2474.

Wang S.Y., Zhang X.X., Zhu T., et al., 2016. Assessment of ecological environment quality inn the Changbai mountain nature reserve based on remote sensing technology. Progress in Geography, 35 (10): 1269-1278.

Xu H. Q., 2013. A remote sensing urban ecological index and its application. Acta Ecologica Sinica, 33(24): 7853-7862.

Ye Y.P., Liu L.J., 2000. A Preliminary Study on Assessment Indicator System of Provincial Eco-Environmental Quality in China, Research of Environmental Sciences, 13(3):33-36.

Zhang C., Xu H.Q., Zhang H., et al, 2015. Fractional vegetation cover change and its ecological effect assessment in a typical reddish soil region of southeastern China: Changting county, Fujian province. Journal of Natural Resources, 30 (6): 917-928. 